This item was submitted to Loughborough's Research Repository by the author.

Items in Figshare are protected by copyright, with all rights reserved, unless otherwise indicated.

\title{
Oxidative dehomologation of aldehydes with oxygen as a terminal oxidant
}

\section{PLEASE CITE THE PUBLISHED VERSION}

https://doi.org/10.1021/acs.orglett.7b03512

\section{PUBLISHER}

(C) American Chemical Society (ACS)

\section{VERSION}

AM (Accepted Manuscript)

\section{PUBLISHER STATEMENT}

This work is made available according to the conditions of the Creative Commons Attribution-NonCommercialNoDerivatives 4.0 International (CC BY-NC-ND 4.0) licence. Full details of this licence are available at: https://creativecommons.org/licenses/by-nc-nd/4.0/

\section{LICENCE}

CC BY-NC-ND 4.0

\section{REPOSITORY RECORD}

Shipilovskikh, Sergei A., Aleksandr E. Rubtsov, and Andrei Malkov. 2019. "Oxidative Dehomologation of Aldehydes with Oxygen as a Terminal Oxidant”. figshare. https://hdl.handle.net/2134/27710. 


\title{
Oxidative Dehomologation of Aldehydes with Oxygen as a Terminal Oxidant
}

\author{
Sergei A. Shipilovskikh, ${ }^{\dagger}$ Aleksandr E. Rubtsov, ${ }^{* \dagger}$ Andrei V. Malkov ${ }^{* \ddagger \S}$ \\ $\dagger$ Department of Chemistry Perm State University, Bukireva 15, Perm 614990, Russia \\ $\ddagger$ Department of Chemistry, Loughborough University, Loughborough, Leics LE11 3TU, UK \\ $\S$ Department of Organic Chemistry, RUDN University, 6 Miklukho-Maklaya Street, Moscow 117198, Russia \\ Supporting Information Placeholder
}
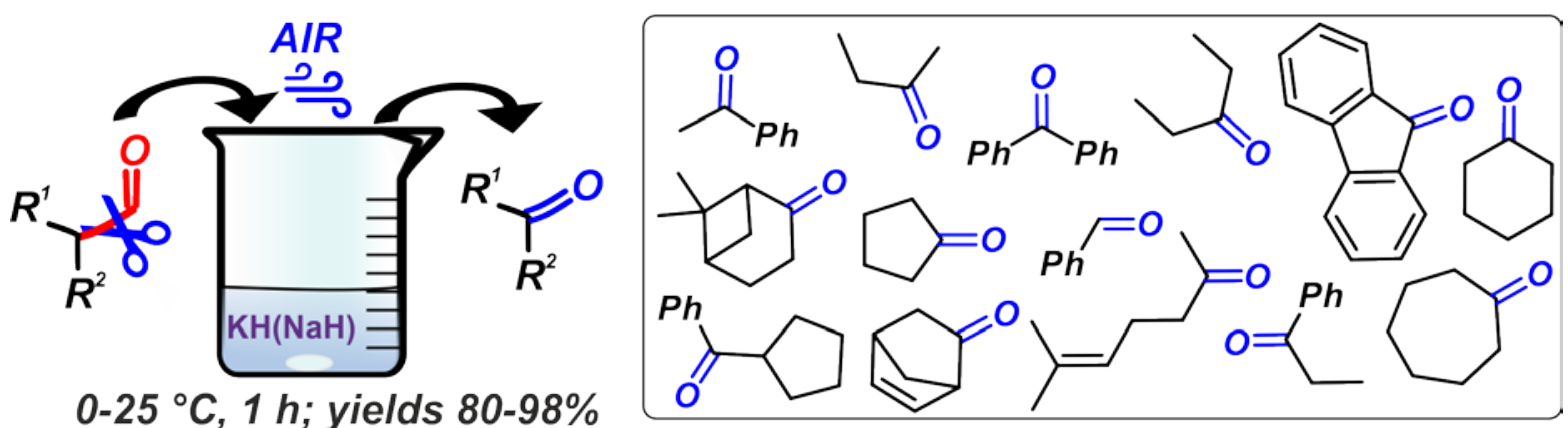

ABSTRACT: A mild, efficient protocol for oxidative cleavage of C-C bond in aldehydes has been developed that employs alkali metal hydrides as reagents and oxygen from air as a terminal oxidant. The method is applicable to a broad substrate range.

Methodologies for efficient and mild cleavage of C-C bonds have a significant synthetic potential. In a specific context, removal of an aldehyde is of a great value because the aldehyde can serve as a temporary activating or directing group in a number of synthetic processes, such as conjugate addition to unsaturated aldehydes or Diels-Alder cycloaddition. ${ }^{1}$ Therefore, there is a demand for practical methods for breaking $\mathrm{C}-\mathrm{C}$ bond in aldehydes with a broad application scope. Commonly, the methods for the oxidative cleavage of aldehydes are based on oxidation of the respective enamines with singlet oxygen or strong oxidants such as periodate or dichromate. ${ }^{2}$ However, they require the prior preparation of enamines and are burdened by the formation of undesired side products. More convenient approaches are based on a direct oxidative cleavage of a $\mathrm{C}-\mathrm{C}$ bond in aldehydes (Scheme 1A). Havare and Plattner ${ }^{3}$ used a combination of iodosobenzene with $\mathrm{HBF}_{4}$ for dehomologation of $\alpha$ arylaldehydes (reaction 1 ). This method required long reaction times, while the need for the aromatic group narrowed the scope. Chi and co-workers ${ }^{4}$ developed a protocol, where the enamine formed in situ from 4-methoxyaniline and the $\alpha$-chiral aldehydes was cleaved using molecular oxygen (reaction 2). However, oxygen had to be used at high pressure to drive the reaction to completion. Xia and coworkers reported on oxidative cleavage of $\mathrm{C}-\mathrm{C}$ bond in aldehydes under conditions of photoredox catalysis using $\mathrm{O}_{2}$ as a terminal oxidant (reaction 3). ${ }^{5}$ In this case, piperidine was used for the in situ formation of enamines. There are other known instances of dehomologation of aldehydes though their scope is limited to single examples. ${ }^{6}$
Scheme 1. Strategies for oxidative cleavage of C-C bond in aldehydes.
A. Previous work<smiles>[R]C([Al])C(=O)[18OH]</smiles><smiles>CC(C)(C)C(C)(C)Oc1ccccc1</smiles><smiles>[R]C(=O)[AlH2]</smiles><smiles>[101In]</smiles>
$\mathrm{R}=\mathrm{H}, \mathrm{Alk}, \mathrm{Ar}$ ref 3
$40-98 \%$ yield<smiles>[R]CC(C=O)C([R])C</smiles>

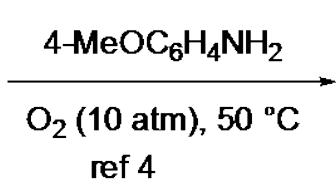<smiles></smiles><smiles>[R]C([R])C=O</smiles>

\section{visible light} $\mathrm{Ru}(\mathrm{bpy})_{3} \mathrm{Cl}_{2}$ piperidine, air, 6-24 h<smiles>[R]C([R])=O</smiles>
$R, R^{\prime}=H$, Alk, Ar ref 5

\section{B. This work}<smiles>[R]C([R])C=O</smiles>

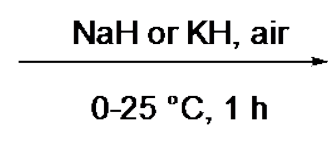<smiles>[R]C([R])=O</smiles>

$R, R^{\prime}=H, A l k, A r$ 
In this work, we present a mild, facile method for oxidative cleavage of aldehydes that utilizes inexpensive reagents and is applicable to a broad substrate range (Scheme 1B).

While investigating a base-mediated equilibration of diastereomeric $\alpha$-chiral aldehydes within our program on total synthesis of marine natural products, ${ }^{7}$ in some instances we observed loss of the aldehyde group. A more detailed investigation into this process led to development of a convenient practical protocol for the dehomologation of aldehydes.

Table 1. Optimization of cyclization conditions. ${ }^{a}$

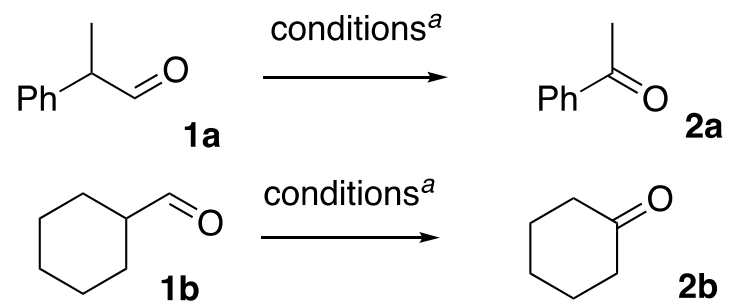

\begin{tabular}{|c|c|c|c|c|}
\hline entry & substrate & base (equiv) & $\begin{array}{l}\text { additive } \\
\text { (1 equiv) }\end{array}$ & $\operatorname{conv}(\%)^{b}$ \\
\hline $1^{c}$ & $1 \mathrm{a}$ & $\mathrm{NaH}(1)$ & - & 40 \\
\hline $2^{c}$ & $1 \mathrm{a}$ & KH (1) & - & 4 \\
\hline $3^{c}$ & $1 \mathrm{a}$ & KH (1) & 18-crown-6 & 64 \\
\hline 4 & $1 \mathrm{a}$ & $\mathrm{NaH}(1)$ & - & 94 \\
\hline 5 & $1 \mathrm{a}$ & KH (1) & 18-crown-6 & 95 \\
\hline 6 & $1 \mathrm{a}$ & $\mathrm{NaH}(0.5)$ & - & 44 \\
\hline 7 & $1 \mathrm{a}$ & $\mathrm{NaH}(1)$ & $\begin{array}{c}\text { dibenzo-18- } \\
\text { crown-6 }\end{array}$ & 97 \\
\hline 8 & $1 \mathrm{a}$ & $\mathrm{NaH}(1.1)$ & - & 99 \\
\hline $9^{d}$ & $1 \mathrm{a}$ & $\mathrm{NaH}(1.1)$ & - & 99 \\
\hline $10^{e}$ & $1 \mathrm{a}$ & $\mathrm{NaH}(1.1)$ & - & 10 \\
\hline 11 & $1 \mathrm{~b}$ & $\mathrm{NaH}(1)$ & - & 3 \\
\hline 12 & $1 \mathrm{~b}$ & $\mathrm{NaH}(3)$ & - & 7 \\
\hline 13 & $1 \mathrm{~b}$ & KH (1) & 18-crown-6 & 61 \\
\hline $14^{c}$ & $1 b$ & KH (1) & 18-crown-6 & 79 \\
\hline $15^{c}$ & $1 b$ & KH (1.1) & 18-crown-6 & 87 \\
\hline $16^{c, f}$ & $1 \mathrm{~b}$ & KH (1.1) & 18-crown-6 & 98 \\
\hline
\end{tabular}

${ }^{a}$ General conditions: substrate ( $0.1 \mathrm{M}$ solution), base, dry ether. The reactions were performed in air at rt for $1 \mathrm{~h}$, unless stated otherwise. ${ }^{b}$ Conversion was calculated from GC. ${ }^{c}$ The reaction was carried out at $0{ }^{\circ} \mathrm{C} .{ }^{d} \mathrm{O}_{2}(1 \mathrm{~atm})$ was used instead of air, the reaction was completed in 30 min. ${ }^{e}$ The reaction was carried out under $\mathrm{N}_{2}$ atmosphere. $f_{0.03} \mathrm{M}$ solution of aldehyde in ether was used.

The initial investigation focused on two model substrates, $\alpha$ arylaldehyde 1a and aliphatic aldehyde $\mathbf{1 b}$ (Table 1$)$. With 1a, the use of $\mathrm{NaH}$ ( 1 equiv) at $0{ }^{\circ} \mathrm{C}$ in $\mathrm{Et}_{2} \mathrm{O}$ after $1 \mathrm{~h}$ resulted in a $40 \%$ conversion to acetophenone 2 a (entry 1 ). Under the same conditions, $\mathrm{KH}$ produced only traces of $\mathbf{2 a}$ (entry 2). However, the addition of 1 equiv of 18 -crown- 6 boosted the reaction performance, leading to a $64 \%$ conversion to 2 a (entry 3). At rt, with both $\mathrm{NaH}$ and $\mathrm{KH} / 18$-crown-6, the reactions were essentially completed after $1 \mathrm{~h}$ (entries 4 and 5). It was found that the base is required in equimolar quantities, as 0.5 equiv of $\mathrm{NaH}$ after 1 h gave only 44\% conversion (entry 6). The use of crown ether with $\mathrm{NaH}$ did not bring any improvement (entry 7). For the optimal performance, a slight excess of $\mathrm{NaH}$ at 1.1 equiv proved to be beneficial (entry 8). Further improvement could be achieved by carrying out the reaction under an atmosphere of pure oxygen $(1 \mathrm{~atm})$. In this instance, the reaction time was shortened to just 30 min (entry 9), though otherwise there was not much difference to the reaction in entry 8 that was run in open air. It is important to highlight the crucial role of oxygen in promoting the cleavage, whether it comes from air or is used as a pure reagent. Thus, running the reaction under a nitrogen atmosphere using otherwise identical conditions resulted in a very low conversion (entry 10).

Aliphatic aldehyde $\mathbf{1 b}$ proved to be a more challenging target. The use of $\mathrm{NaH}$ gave only traces of product (entry 11). Increasing the amount of base to 3 equiv failed to bring any improvement (entry 12). Promising results were obtained with a KH/18crown-6 combination. At rt, with 1 equiv of $\mathrm{KH}$, a conversion of $61 \%$ was achieved (entry 13), which increased to $79 \%$ by lowering the reaction temperature to $0{ }^{\circ} \mathrm{C}$ (entry 14). The use of a slight excess of $\mathrm{KH}$ (1.1 equiv) brought the conversion to $87 \%$ (entry 15). Finally, a complete conversion was attained when a more diluted solution of substrate was employed, $0.03 \mathrm{M}$ compared to $0.1 \mathrm{M}$ in the previous experiments (entry 16). These conditions were taken as optimal for the cleavage of $\mathbf{1 b}$ to $\mathbf{2} \mathbf{b}$.

Next, the investigation turned to establishing the scope and limitations of the method. The results are presented in Table 2.

Aldehydes 1c-f with at least one aromatic substituent in the $\alpha$-position reacted uneventfully exhibiting similar reactivity to the model substrate 1a. (entries 1-5). Excellent yields of the respective ketones were obtained using $\mathrm{NaH}$ as a base and air as a terminal oxidant. The reactions were complete in under $1 \mathrm{~h}$ at rt. However, with phenylacetaldehyde 19 these conditions proved to be inefficient resulting in a poor conversion. Oxidative cleavage in $\mathbf{1 g}$ could be achieved by replacing $\mathrm{NaH}$ by a combination of $\mathrm{KH}$ with 18-crown-6, under the conditions developed for aliphatic aldehyde $\mathbf{1 b}$ (Table 1, entry 16), to furnish benzaldehyde $\mathbf{2 g}$ in $80 \%$ yield (Table 2 , entry 6 ).

Moving to the aliphatic series and employing conditions from Table 1 entry 16, analogues of $\mathbf{1 b}$ with different ring sizes, such as aldehydes $\mathbf{1 h}$ and $\mathbf{1 i}$, were successfully converted to the respective ketones $\mathbf{2 h}$ and $\mathbf{2} \mathbf{i}$ (entries 8, 9). It is worth noting that isolation of aliphatic ketones proved to be cumbersome due to their volatility. Therefore, the ketones of the aliphatic series were isolated and characterized as their 2,4-dinitrophenylhydrazones. Acyclic aldehydes $\mathbf{1 j}$ and $\mathbf{1 k}$ exhibited similar reactivity (entries 10, 11), as did terpene derivatives $\mathbf{1 l}$ and $\mathbf{1 m}$ (entries 12, 13).

Aldehyde 1n is the product of a Diels-Alder cycloaddition between cyclopentadiene and acrolein. The reaction can be carried out enantioselectively where the aldehyde serves as a convenient handle for a chiral catalyst. ${ }^{8}$ In the past, conversion of the adducts of type $\mathbf{1 n}$ to ketones like $\mathbf{2 n}$ would require several synthetic steps. ${ }^{9}$ Therefore, it was of interest to examine the oxidative dehomologation of $\mathbf{1 n}$. The reaction proceeded 
smoothly yielding ketone 2n in 85\% (entry 14), which represents a considerable shortcut to this valuable synthetic building block.

Table 2. Scope of the Oxidative Cleavage Conditions. ${ }^{\text {a }}$

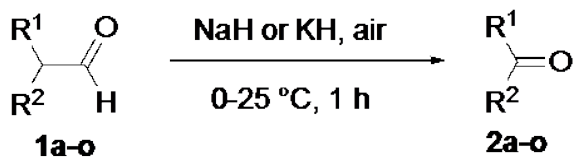

(i)

${ }^{a}$ Reaction conditions: A - aldehyde (1 equiv, $0.1 \mathrm{M}$ in anhydrous $\mathrm{Et}_{2} \mathrm{O}$ ), $\mathrm{NaH}$ (1.1 equiv), air, rt, $1 \mathrm{~h}$; $\mathrm{B}$ - aldehyde (1 equiv, $0.03 \mathrm{M}$ in anhydrous $\left.\mathrm{E}_{\mathrm{t} 2} \mathrm{O}\right), \mathrm{KH}$ (1.1 equiv), 18-crown-6 (1 equiv), air, 0
${ }^{\circ} \mathrm{C}, 1$ h. ${ }^{b}$ Isolated yield. ${ }^{c}$ Yield of the respective 2,4-dinitrophenylhydrazone. ${ }^{d}$ Conversion by GC.

Not all the tested substrates reacted well in the oxidative cleavage reaction. Thus, hydrocinnamyl aldehyde $\mathbf{1 0}$ gave a complex product mixture, where, according to the GC-MS analysis, conversion to the desired ketone 20 was about 32\% (entry 15). The reason for this anomalous behavior of $\mathbf{1 0}$ is not clear at the moment.

The reaction mechanism has not been investigated but it is likely to involve formation of the enolate first, followed by autoxidation ${ }^{10}$ and intermediate formation of oxetane, analogously to the route proposed for the cleavage of enamines, ${ }^{4,11}$ to furnish ketone $\mathbf{2}$ and a formate salt of $\mathrm{Na}$ or $\mathrm{K}$.

In conclusion, we have developed a mild, facile protocol for an aerobic oxidative cleavage of $\mathrm{C}$ - $\mathrm{C}$ bond in aldehydes producing the respective ketones. The reaction works well with a wide range of aldehydes. It avoids the use of transition metals catalysts and the only byproduct generated during the reaction is a water-soluble alkali formate.

\section{ASSOCIATED CONTENT}

\section{Supporting Information}

Experimental procedures; ${ }^{1} \mathrm{H}$ and ${ }^{13} \mathrm{C}$ NMR spectra for new compounds.

The Supporting Information is available free of charge on the ACS Publications website.

\section{AUTHOR INFORMATION}

\section{Corresponding Author}

*E-mail: A.Malkov@lboro.ac.uk

*E-mail: Rubtsov@psu.ru

\section{Author Contributions}

The manuscript was written through contributions of all authors.

\section{ACKNOWLEDGMENT}

The authors thank Russian Science Foundation for grant 15-1300092. We also acknowledge RUDN University and the Ministry of Education and Science of the Russian Federation (the Agreement 02.A03.21.0008) for access to the analytical facilities (HRMS).

\section{REFERENCES}

1. For selected examples on the use of dehomologated products in total synthesis, see: (a) Baars, H.; Classen, M. J.; Aggarwal, V. K., Org. Lett. 2017, 19, 6008-6011; (b) Nicolaou, K. C.; Pulukuri, K. K.; Yu, R.; Rigol, S.; Heretsch, P.; Grove, C. I.; Hale, C. R.; ElMarrouni, A., Chem. Eur. J. 2016, 22, 8559-70.

2. (a) Vetelino, M. G.; Coe, J. W., Tetrahedron Lett. 1994, 35 219-222; (b) Wooten, J.; Savitsky, G. B.; Jacobus, J., J. Am. Chem. Soc. 1975, 97, 5027-5028; (c) Huber, J. E., Tetrahedron Lett. 1968, 9, $3271-$ 3272; (d) Foote, C. S.; Lin, J. W. P., Tetrahedron Lett. 1968, 9, 32673270; (e) Witkop, B., J. Am. Chem. Soc. 1956, 78, 2873-2882; (f) Slomp, G., Jr.; Shealy, Y. F.; Johnson, J. L.; Donia, R. A.; Johnson, B. A.; Holysz, R. P.; Pederson, R. L.; Jensen, A. O.; Ott, A. C., J. Am. Chem. Soc. 1955, 77, 1216-1221.

3. Havare, N.; Plattner, D. A., Org. Lett. 2012, 14, 5078-5081.

4. Tiwari, B.; Zhang, J.; Chi, Y. R., Angew. Chem., Int. Ed. 2012, 51, 1911-4. 
5. Sun, H.; Yang, C.; Gao, F.; Li, Z.; Xia, W., Org. Lett. 2013, 15, 624-627.

6. (a) Althaus, M.; Togni, A.; Mezzetti, A., J. Fluorine Chem. 2009, 130, 702-707; (b) Diaz-Rodriguez, A.; Rios-Lombardia, N.; Sattler, J. H.; Lavandera, I.; Gotor-Fernandez, V.; Kroutil, W.; Gotor, V., Catal. Sci. Technol. 2015, 5, 1443-1446; (c) Fraile, J. M.; Garcia, N.; Mayoral, J. A.; Santomauro, F. G.; Guidotti, M., ACS Catal. 2015, 5, 3552-3561; (d) Fuchs, C. S.; Hollauf, M.; Meissner, M.; Simon, R. C.; Besset, T.; Reek, J. N. H.; Riethorst, W.; Zepeck, F.; Kroutil, W., Adv. Synth. Catal. 2014, 356, 2257-2265; (e) Miles, K. C.; Abrams, M. L.; Landis, C. R.; Stahl, S. S., Org. Lett. 2016, 18, 3590-3593; (f) Posner, G. H.; Lee, J. K.; White, M. C.; Hutchings, R. H.; Dai, H.; Kachinski, J. L.; Dolan, P.; Kensler, T. W., J. Org. Chem. 1997, 62, 3291-3298; (g) Qin, Y.; Cheng, Y.; Luo, X.; Li, M.; Xie, Y.; Gao, Y., Synlett 2015, 26, 1900-1904; (h) Shokri, A.; Que, L., J. Am. Chem. Soc. 2015, 137, 7686-7691; (i) Tcho, W.-Y.; Wang, B.; Lee, Y.-M.; Cho, K.-B.; Shearer, J.; Nam, W., Dalton Trans. 2016, 45, 14511-14515; (j) Tokunaga, M.; Aoyama, H.; Shirogane, Y.; Obora, Y.; Tsuji, Y., Catal. Today 2006, 117, 138-140; (k) Tokunaga, M.; Shirogane, Y.; Aoyama, H.; Obora, Y.; Tsuji, Y., J. Organomet. Chem. 2005, 690, 5378-5382; (l) Van Rheenen, V., Tetrahedron Lett. 1969, 10, 985-988.

7. (a) Incerti-Pradillos, C. A.; Kabeshov, M. A.; O'Hora, P. S.; Shipilovskikh, S. A.; Rubtsov, A. E.; Drobkova, V. A.; Balandina, S. Y.; Malkov, A. V., Chem. Eur. J. 2016, 22, 14390-6; (b) O'Hora, P. S.; Incerti-Pradillos, C. A.; Kabeshov, M. A.; Shipilovskikh, S. A.; Rubtsov, A. E.; Elsegood, M. R.; Malkov, A. V., Chem. Eur. J. 2015, 21, 4551-5.

8. (a) Hatano, M.; Mizuno, T.; Izumiseki, A.; Usami, R.; Asai, T.; Akakura, M.; Ishihara, K., Angew. Chem., Int. Ed. 2011, 50, 1218992; (b) Maruoka, K.; Murase, N.; Yamamoto, H., J. Org. Chem. 1993, 58, 2938-2939.

9. (a) Corey, E. J.; Loh, T. P., J. Am. Chem. Soc. 1991, 113, 8966-8967; (b) Corey, E. J.; Ravindranathan, T.; Terashima, S., J. Am. Chem. Soc. 1971, 93, 4326-4327.

10. Hammond, C. J.; Lindsay Smith, J. R.; Nagatomi, E.; Stark, M. S.; Waddington, D. J., New J. Chem. 2006, 30, 741.

11. Zhang, C.; Xu, Z.; Shen, T.; Wu, G.; Zhang, L.; Jiao, N., Org. Lett. 2012, 14, 2362-5. 